Tersedia online di: http://ejournal-balitbang.kkp.go.id/index.php/JP
e-mail:jurnalpari@gmail.com
JURNAL PARI
Volume 4 Nomor 2 Desember 2018
p-ISSN: 2502-0730
e-ISSN : 2549-0133

\title{
PATHFINDER MEMBANTU PENELITI MEMPEROLEH INFORMASI SECARA CEPAT
}

\author{
Fathmi*) \\ Perpustakaan Nasional Republik Indonesia \\ Diterima tanggal : 13 September 2018 Diterima setelah perbaikan : 22 November 2018 \\ disetujui terbit : 13 Desember 2018
}

\begin{abstract}
ABSTRAK
Pathfinder atau panduan pustaka adalah salah satu alat bantu bagi pemustaka untuk memperoleh informasi secara cepat, mandiri, dan dirancang untuk membimbing pemustaka pada tahap awal penelusuran. Tujuan pathfinder membantu pemustaka yang akan mencari informasi mengenai masalah khusus tetapi belum memahami dan mengenal sumber informasi di perpustakaan. Pathfinder memuat sumber-sumber bibliografi yang berhubungan dengan subjek tertentu yang berasal dari buku, makalah, terbitan berkala, sumber referensi, website, audio visual, dan sebagainya. Informasi yang dimuat pada pathfinder: judul pathfinder, ruang lingkup, jenis sumber informasi, judul sumber informasi, deskripsi fisik, nomor panggil, anotasi, dan lokasi.
\end{abstract}

Kata kunci: pathfinder; panduan pustaka.

\begin{abstract}
Pathfinder or library guide is one of the tools for users to get information quickly and independently. Pathfinder is designed to guide users in the early stages of search. Pathfinder objectives help users who do not understand and know the source of information in the library when to find information about specific problems. Pathfinder contains bibliographic sources related to certain subjects that come from books, papers, periodicals, reference sources, websites, audio visuals, and so on. Information that contained in the pathfinder are pathfinder title, scope, type of information source, source title information, physical description, call number, annotation, and location.
\end{abstract}

Keyword: Pathfinder; library guide. 
Memanjakan pemustaka merupakan keharusan bagi perpustakaan saat ini. Salah satu bentuk memanjakan pemustaka adalah dengan menyediakan sarana temu kembali untuk mempercepat dalam menemukan informasi. Pemustaka memiliki latar belakang pendidikan, wawasan dan pengalaman yang berbeda, sehingga tingkat kebutuhan informasi mereka juga berbeda. Pemustaka Perpustakaan Badan Riset dan Sumber Daya Manusia dan Perikanan Kementerian Kelautan dan Perikanan sebagian besar adalah peneliti yang sesungguhnya memiliki waktu sangat sedikit untuk menelusur informasi di perpustakaan. Untuk membantu peneliti dalam memperoleh informasi yang dibutuhkannya secara cepat dan tepat, dan untuk mengoptimalkan sumber daya koleksi yang dimiliki perpustakaan, maka kehadiran pathfinder sangat dibutuhkan.

Pathfinder, menurut Kamus Besar Bahasa Indonesia ( tahun ... halama...) berasal dari turunan kata "path" yang berarti "jalan sempit/kecil" dan "finder" yang berarti "penemu", secara harfiah pathfinder berarti penemu jalan kecil. Fathfinder dikenal dengan nama lain library pathfinder, panduan pustaka, panduan subjek, libguide. Dictionary for Library and Information Science : 527 mendefinisikan pathfinder "A subject bibliography design to lead the user through the process of a researchin a specific topic, or any topic in a given field or discipline, usually in a systematic, step by-step way, making use of the best finding tools the library has to offer. Pathfinder mau be printed or available online". Jika diterjemahkan secara bebas "Sebuah bibliografi subjek yang dirancang untuk memandu pemustaka melalui proses meneliti topik tertentu, atau topik yang diberikan dalam bidang atau disiplin tertentu, biasanya secara sistematis, langkah demi langkah, memanfaatkan sarana perpustakaan. Pathfinder dapat disajikan dalam bentuk tercetak atau online".

Secara spesifik Peraturan Kepala Perpustakaan Nasional RI Nomor 11 Tahun 2015 Tentang Petunjuk Teknis Jabatan Fungsional Pustakawan (2015 : 79) memasukkan butir "membuat panduan pustaka (pathfinder)" sebagai butir kegiatan pustakawan madya. Panduan pustaka adalah terjemahan dari bahasa Inggris library pathfinder yang merupakan checklist pengantar untuk subjek-subjek tertentu dan dirancang untuk membimbing para pemustaka pada tahap awal penelusuran literatur. Dijelaskan di Juknis tersebut bahwa membuat panduan pustaka (pathfinder)" adalah kegiatan membuat panduan pustaka yang berfungsi sebagai panduan awal dan alat bantu bagi pemustaka untuk melakukan penelusuran secara mandiri. Tujuannya adalah untuk membantu pemustaka yang akan mencari informasi mengenai masalah khusus tetapi belum memahami dan mengenal sumber informasi di perpustakaan. Pathfinder memuat sumber-sumber bibliografi yang berhubungan dengan subjek tertentu yang berasal dari buku, makalah, terbitan berkala, sumber referensi, website, audio visual, dan sebagainya. Masing-masing koleksi perpustakaan tersebut dilengkapi dengan data bibliografi.

Sri Rohyanti Sulaikha (2004) dalam Purwono (2009) menjelaskan bahwa pathfinder merupakan salah satu bentuk upaya pustakawan untuk meningkatkan jasa pelayanan referensi (rujukan) kepada pemustaka dalam menemukan kembali informasi di perpustakaan. Penggagas dari library pathfinder adalah Charles $\mathrm{H}$. Stevens, seorang Asociate Director dari Library Development, Project Intrex, Massachusets Institute of Technology (MIT) Amerika Serikat. yang bernama Charles $\mathrm{H}$. Stevens. Gagasan tersebut kemudian dikembangkan oleh staf dari Model Library Project, Project Intrex.

Pathfinder merupakan sarana bantu baik cetak maupun online dalam pelayanan referensi. Oleh karena itu pathfinder dalam bentuk buku atau leafleat diletakkan di ruang referensi atau di meja informasi. Bila dilihat dari bentuk penyajiannya, pathfinder mirip bibliografi konvensional. Perbedaanya terletak pada cara pencarian dan pemilihan sumbernya, dilengkapi dengan cakupan atau anotasi, serta pencatatan notasi kelas yang tepat sebagai pembuka penelusuran.

Pathfinder bermanfaat baik bagi pemustaka maupun bagi pustakawan. Bagi pemustaka manfaat pathfinder antara lain:

1. Mempercepat mendapatkan informasi yang diperlukan tentang sebuah subjek, karena pathfinder disusun berdasarkan subjek yang spesifik;

2. Pemustaka dapat memperoleh gambaran isi dalam judul-judul yang didaftar dalam sebuah pathfinder, karena dilengkapi dengan cakupan atau anotasi;

3. Pemustaka secara cepat dapat menemukan langsung koleksi yang diminatinya, karena pathfinder memandu pemustaka dengan adanya nomor panggil dan lokasi koleksi tersebut diletakkan;

4. Memperluas pengetahuan pemustaka tentang sebuah subjek, karena pathfinder yang dibuat oleh pustakawan tidak hanya berasal dari buku, akan tetapi semua jenis koleksi yang dimiliki perpustakaan tersebut berasal dari buku, makalah, terbitan berkala, sumber referensi, website, audio visual, dan sebagainya; 
5. Membantu pemustaka untuk mengetahui bibliografi koleksi, karena pathfinder dilengkapi dengan bibliografi koleksi sehingga memudahkan pemustaka dalam pembuatan daftar pustaka;

6. Memberikan kepuasan bagi pemustaka dalam pemenuhan informasinya, karena ketika mereka mencari isu-isu atau subjek penting sudah terkumpul menjadi satu di sebuah pathfinder.

Manfaat pathfinder bagi pustakawan antara lain:

1. Pathfinder sangat membantu pustakawan dalam memberikan informasi kepada pemustaka secara cepat dan tepat, karena informasi dalam suatu subjek sudah terkumpul dalam satu daftar berasal dari buku, makalah, terbitan berkala, sumber referensi, website, audio visual, lengkap dengan anotasinya.

2. Sisi lain, manfaat pathfinder bagi pustakawan adalah mendapatkan angka kredit untuk memenuhi kewajibannya mengumpulkan DUPAK, karena penilaian angka kredit didasarkan pada seberapa banyak entri yang dapat dihasilkan oleh pusakawan.

\section{Penyusunan Pathfinder}

Langkah-langkah penyusun pathfinder dimulai dengan menentukan topik yang akan dipilih. Topik yang dipilih tidak terlalu luas atau terlalu sempit. Dari topik yang telah ditetapkan, tentukan apakah literatur secara komprehensif, selektif, retrospektif atau current. Semua sumber yang ada di perpustakaan harus dimasukkan ke dalam pathfinder tersebut.

Berikut urutan dalam membuat pathfinder:

1. Penyusunan panduan pustaka (pathfinder) dapat diawali dengan membuat judul panduan yang diletakkan di sebelah sudut kanan atas.

2. Panduan dilanjutkan dengan mencatat ruang lingkup subjeknya, diikuti dengan sebuah entri yang mengacu kepada suatu sumber yang membuat pembahasan masalahnya secara umum dan yang cocok bagi seseorang yang belum mengetahui cakupan subjeknya. Cakupan atau ruang lingkup biasanya diambil dari sebuah rujukan berbentuk kamus atau ensiklopedia, diikuti dengan memberikan deskripsi bibliografi dari cakupan yang dikutip, bahkan sampai kepada sandi buku (call number) yang sesuai dengan aturan di perpustakaan dimana koleksi tersebut berada serta lokasi sumber rujukan yang digunakan dalam menulis cakupan.

3. Acuan diikuti dengan petunjuk mengenai tajuk subjek dan nomor kelasnya yang sesuai dengan topik yang dibuat yang dapat digunakan untuk mencari koleksi yang terkait dengan subjek yang ditulis. Entri tersebut dapat diambil lewat kartukartu katalog manual maupun katalog terbacakan mesin komputer atau OPAC (Online Public Acsess Catalog).

4. Setelah entri-entri tajuk subjek dan nomor kelas selesai, kemudian melakukan pendataan koleksi mulai dari buku teks sampai kepada majalah indeks, yang meliputi:

a. Buku-buku teks yang utama, atau buku-buku bacaan wajib

b. Buku-buku teks anjuran

c. Buku pegangan (handbook atau manual), ensiklopedia dan kamus khusus

d. Bibliografi

e. Majalah indeks dan abstrak, terutama yang mendaftar karangan ilmiah yang dimuat di jurnal

f. Majalah/jurnal primer

g. Laporan pertemuan ilmiah (prosiding seminar)

h. Majalah indeks dan abstrak yang mendaftar laporan teknis

Pendataan koleksi (buku teks, buku pegangan, bibliografi, majalah indeks dan abstrak, majalah/jurnal primer, laporan pertemuan ilmiah, majalah indeks dan abstrak) harus selalu disertai dengan deskripsi bibliografi lengkap dan lokasi dimana koleksi tersebut berada. Hal ini dimaksudkan untuk memudahkan pemustaka mendapatkan kolesi, sehingga pemustaka dapat langsung mencari koleksi ke sumber rujukan, kalau perlu sertakan juga pada rak nomor berapa koleksi tersebut diletakkan.

\section{Format Pathfinder}

Format pathfinder sesuai dengan Peraturan Kepala Perpustakaan Nasional RI Nomor 11 Tahun 2015 Tentang Petunjuk Teknis Jabatan Fungsional Pustakawan memuat informasi: judul pathfinder, ruang lingkup, jenis sumber informasi, judul sumber informasi, deskripsi fisik, nomor panggil, anotasi, dan lokasi.

Contoh:

[judul ]

\section{WAYANG}

\section{Ruang lingkup pembahasan}

Wayang salah satu seni budaya bangsa Indonesia yang paling menonjol. Budaya wayang meliputi seni peran, seni suara, seni tutur, seni sastra, seni lukis, seni pahat, dan juga seni perlambang. Budaya wayang, yang terus berkembang dari zaman ke zaman, juga merupakan media penerangan, dakwah, pendidikan, pemahaman filsafat, serta hiburan. 
Jenis-jenis wayang:

a. Wayang Purwa

Wayang Purwa disebut juga wayang kulit karena terbuat dari kulit lembu. Penyaduran sumber cerita dari Ramayana dan Mahabharata ke dalam bahasa Jawa Kuna dilakukan pada masa pemerintahan Jayabaya. Pujangga terkenal pada masa itu adalah empu Sedah, empu Panuluh, dan empu Kanwa. Sunan Kalijaga salah seorang wali sanga adalah orang yang pertama kali menciptakan wayang dari kulit lembu. Selain kulit lembu ada juga yang menggunakan kulit kerbau.

b. Wayang Golek

Banyak orang yang menyebut wayang golek dengan sebutan wayang Tengul. Wayang ini terbuat dari kayu dan diberi baju selayaknya manusia. Sumbernya diambil dari sejarah, misalnya cerita Untung Surapati, Batavia, Sultan Agung, Trunajaya, dan lain-lain. Wayang golek tidak menggunakan layar seperti wayang kulit.

c. Dst.

2. Sumber kutipan

R 791.5303

NAN Nanda MH

e Ensiklopedi Wayang / Nanda MH. Yogyakarta : Absolut, 2010. $221 \mathrm{hlm}$. : ilus. ; $19 \mathrm{~cm}$. Dilengkapi dengan gambar, tokohtokoh wayang,kisah Ramayana dan Mahabarata

Bibliografi : hlm. 319

Wayang - Ensiklopedi

Lokasi : Lantai 15 Koleksi Perpustakaan Nasional RI, Jl. Merdeka Selatan No. 11 Jakpus

Informasi mengenai wayang dapat dicari di:

I. Buku teks

\begin{tabular}{|c|c|c|c|c|c|c|}
\hline NO & $\begin{array}{c}\text { JUDUL / } \\
\text { PENANGGUNG } \\
\text { JAWAB }\end{array}$ & $\begin{array}{l}\text { PENER- } \\
\text { BITAN }\end{array}$ & $\begin{array}{l}\text { DESKRIP } \\
\text { SI FISIK }\end{array}$ & $\begin{array}{c}\text { NOMOR } \\
\text { PANGGIL }\end{array}$ & LOKASI & ANOTASI \\
\hline 1 & $\begin{array}{l}\text { Arti makna tokoh } \\
\text { pewayangan } \\
\text { Mahabrata dalam } \\
\text { pembentukan dan } \\
\text { pembinaan watak / } \\
\text { Made Purna \& Sri } \\
\text { Guritno }\end{array}$ & $\begin{array}{l}\text { Jakarta: } \\
\text { Depdikbud, } \\
1997\end{array}$ & $\begin{array}{l}\text { ix, } 110 \mathrm{hlm} . \\
; 21 \mathrm{~cm}\end{array}$ & $\begin{array}{l}791.53 \\
\text { MAD a }\end{array}$ & $\begin{array}{l}\text { Lantai } 22 \\
\text { Perpusna } \\
\text { s } \\
\text { Merdeka } \\
\text { Selatan } \\
\text { No. } 11\end{array}$ & $\begin{array}{l}\text { Wayang (khususnya } \\
\text { dalam cerita Mahabrata) } \\
\text { mempunyai peranan yang } \\
\text { sangat besar dalam } \\
\text { kehidupan masyarakat } \\
\text { pendukungnya, baik di } \\
\text { kalangan kaum pria } \\
\text { maupun wanita. } \\
\text { Menampilkan beberapa } \\
\text { tokoh wayang pria, dan } \\
\text { beberapa tokoh wayang } \\
\text { wanita. Pada jaman } \\
\text { Mahabrata kaum wanita } \\
\text { dilukiskan sebagai bumi, } \\
\text { sedang kaum laki-laki } \\
\text { sebagai langit. Senang } \\
\text { atau tidak, langit dapat } \\
\text { mencurahkan hujan yang } \\
\text { lebat atau mengirimkan } \\
\text { sinar matahari yang terik. } \\
\text { lbu pertiwi tetap } \\
\text { menerimanya dengan } \\
\text { sabar. }\end{array}$ \\
\hline
\end{tabular}


II. Buku pegangan (handbook atau manual), ensiklopedia dan kamus khusus

\begin{tabular}{|c|c|c|c|c|c|c|}
\hline NO & $\begin{array}{c}\text { JUDUL / } \\
\text { PENANGGUNG } \\
\text { JAWAB }\end{array}$ & PENERBITAN & $\begin{array}{l}\text { DESKRIPSI } \\
\text { FISIK }\end{array}$ & $\begin{array}{l}\text { NOMOR } \\
\text { PANGGIL }\end{array}$ & LOKASI & ANOTASI \\
\hline 1 & $\begin{array}{l}\text { Ensiklopedi wayang } \\
\text { / Nanda MH }\end{array}$ & $\begin{array}{l}\text { Yogyakarta : } \\
\text { Absolut, } 2010\end{array}$ & $\begin{array}{l}221 \mathrm{hlm} ; 21 \\
\mathrm{~cm} .\end{array}$ & $\begin{array}{l}\text { R } \\
791.5303 \\
\text { NAN e }\end{array}$ & $\begin{array}{l}\text { Lantai } 15 \\
\text { Perpusna } \\
\text { s } \\
\text { Merdeka } \\
\text { Selatan } \\
\text { No. } 11\end{array}$ & $\begin{array}{l}\text { Wayang salah satu } \\
\text { seni budaya } \\
\text { bangsa Indonesia } \\
\text { yang paling } \\
\text { menonjol. Budaya } \\
\text { wayang meliputi } \\
\text { seni peran, seni } \\
\text { suara, seni tutur, } \\
\text { seni sastra, seni } \\
\text { lukis, seni pahat, } \\
\text { dan juga seni } \\
\text { perlambang. }\end{array}$ \\
\hline
\end{tabular}

III. Bibliografi

\begin{tabular}{|c|c|c|c|c|c|c|}
\hline NO & $\begin{array}{c}\text { JUDUL / } \\
\text { PENANGGUNG } \\
\text { JAWAB }\end{array}$ & PENERBITAN & $\begin{array}{l}\text { DESKRIP } \\
\text { SI FISIK }\end{array}$ & $\begin{array}{l}\text { NOMOR } \\
\text { PANGGIL }\end{array}$ & LOKASI & ANOTASI \\
\hline & $\begin{array}{l}\text { Daftar artikel } \\
\text { mengenai wajang } \\
\text { koleksi } \\
\text { Perpustakaan } \\
\text { Museum Nasional / } \\
\text { penyusun, Wartini } \\
\text { Santoso }\end{array}$ & $\begin{array}{l}\text { Jakarta: } \\
\text { Perpustakaan } \\
\text { Museum } \\
\text { Nasional, } 1980\end{array}$ & $\begin{array}{l}21 \mathrm{hlm} ; 28 \\
\mathrm{~cm} .\end{array}$ & $\begin{array}{l}\text { R } 791.53 \\
\text { DAF }\end{array}$ & $\begin{array}{l}\text { Lantai } \\
15 \\
\text { Perpusn } \\
\text { as } \\
\text { Merdek } \\
\text { a } \\
\text { Selatan } \\
\text { No. } 11\end{array}$ & $\begin{array}{l}\text { Merupakan } \\
\text { kumpulan daftar } \\
\text { artikel mengenai } \\
\text { wayang yang } \\
\text { diambil dari buku- } \\
\text { buku dan artikel } \\
\text { yang terdapat dari } \\
\text { beberapa majalah. } \\
\text { Penyusunannya } \\
\text { berdasarkan abjad } \\
\text { penulis (untuk } \\
\text { artikel yang ada } \\
\text { penulisnya) serta } \\
\text { langsung judul } \\
\text { (untuk artikel yang } \\
\text { tidak diketahui } \\
\text { penulilsnya). }\end{array}$ \\
\hline
\end{tabular}

IV. Majalah indeks dan abstrak, terutama yang mendaftar karangan ilmiah yang dimuat di jurnal

V. Majalah/jurnal primer

VI. Laporan pertemuan ilmiah (prosiding seminar)

VII.Majalah indeks dan abstrak yang mendaftar laporan teknis

Jika tampilan dengan menggunakan kolomkolom dianggap kurang disukai, tampilan dapat diubah dengan bentuk di bawah ini:

Arti makna tokoh pewayangan Mahabrata dalam pembentukan dan pembinaan watak / Made Purna \& Sri Guritno. - Jakarta : Depdikbud, 1997. — ix, $110 \mathrm{hlm}$. ; $21 \mathrm{~cm}$

Nomor panggil: 791.53 MAD a
Lokasi: Lantai 22 Perpusnas Merdeka Selatan No. 11

Anotasi:

Wayang (khususnya dalam cerita Mahabrata) mempunyai peranan yang sangat besar dalam kehidupan masyarakat pendukungnya, baik di kalangan kaum pria maupun wanita. Menampilkan beberapa tokoh wayang pria, dan beberapa tokoh wayang wanita. Pada jaman Mahabrata kaum wanita dilukiskan sebagai bumi, sedang kaum laki-laki sebagai langit. Senang atau tidak, langit dapat mencurahkan hujan yang lebat atau mengirimkan sinar matahari yang terik. Ibu pertiwi tetap menerimanya dengan sabar. Lukisan kesabaran yang penuh perasaan ini dapat disimak dari tokoh Kunthi dan Madri. 


\section{DAFTAR PUSTAKA}

Peraturan Kepala Perpustakaan Nasional Republik Indonesia Nomor 11 Tahun 2015 Tentang

Petunjuk Teknis Jabatan Fungsional Pustakawan Dan Angka Kreditnya. 2015. Jakarta :

Perpustakaan Nasional Republik Indonesia

Peraturan Kepala Perpustakaan Nasional Republik Indonesia Nomor 11 Tahun 2018 Tentang

Pedoman Penilaian Angka Kredit Unsur Pelayanan Perpustakaan. 2017. Jakarta :

Perpustakaan Nasional Republik Indonesia

Purwono. 2007. Pemaknaan Buku Bagi Masyarakat Pembelajar. Yogyakarta : Sagung Seto

Syihabuddin Qolyubi [et al.]. 2007. Dasar-Dasar Ilmu Perpustakaan Dan Informasi. Yogyakarta : Jurusan Ilmu Perpustakaan dan Informasi, Fakultas Adab, UIN Sunan Kalijaga 